\title{
(RE)CONCEITUANDO MULTILETRAMENTOS, CRÍTICA E ENSINO DE LÍNGUAS EM UM CURSO DE FORMAÇÃO CONTINUADA
}

\author{
Marlene de Almeida Augusto de Souza*
}

\begin{abstract}
Resumo: Nas últimas duas décadas, o ensino de línguas tem sido analisado considerando as discussões sobre (multi)letramentos crítico (CERVETTI; PARDALES; DAMICO, 2001; COPE; KALANTZIS, 1999; LANKSHEAR; KNOBEL, 2003; LUKE; FREEBODY, 1997). Considerando que essas pesquisas são relativamente recentes, entendo que seja necessário apresentar esses conceitos em cursos de formação continuada de professores para que eles tenham a oportunidade de (re)pensar, (res)significar suas práticas pedagógicas. Neste artigo, analiso as falas dos professores participantes de um curso quanto aos significados de multiletramentos; de crítica e do papel dessas questões no ensino de línguas.
\end{abstract}

Palavras-chave: Multiletramento crítico. Ensino de línguas. Formação de professores.

\begin{abstract}
In the last two decades, the language teaching process has been analyzed considering the critical multiliteracies researches (CERVETTI; PARDALES; DAMICO, 2001; COPE; KALANTZIS, 1999; LANKSHEAR; KNOBEL, 2003; LUKE; FREEBODY, 1997. Considering that these researches are relatively new, I think that is necessary to discuss critical multiliteracies in teacher continuing education so that teachers can (re)think and (re)signify their own pedagogical practices. In this article, I analyse the speeches of teachers, who attended a course, concerning multiliteracies, critic and the role of these aspects in language teaching.
\end{abstract}

Keywords: Critical multiliteracy. Language teaching. Teacher education.

\section{Introdução}

Pesquisas sobre (multi)letramentos críticos e ensino de línguas estrangeiras são relativamente recentes no exterior (CERVETTI; PARDALLES; DAMICO, 2001; LUKE; FREEBODY, 1997; SNYDER, 2002) e no Brasil (MENEZES DE SOUZA; MONTE MÓR, 2006; MENEZES DE SOUZA; ANDREOTTI, 2008; JORDÃO, 2008; FESTINO, 2008; TAKAKI, 2008). Tal fato indica que a maioria dos professores atuando não teve acesso a essas pesquisas durante sua formação inicial.

O encaminhamento de discussões sobre os multiletramentos críticos em cursos de formação continuada pode, portanto, ser uma oportunidade de os professores terem interlocutores para discutirem teoricamente sobre essas novas pesquisas e (re)pensarem, (res)significarem suas práticas pedagógicas como proposto por esta teoria.

Considerando-se essas questões, foi oferecido durante o segundo semestre de 2010 um curso de extensão - Multiletramentos Críticos e Ensino de Línguas - que era parte do Programa de Formação de Professores (Licenciatura) de uma universidade pública da cidade de São Paulo.

O curso tinha como público-alvo professores (em formação) de línguas, incluindo tanto língua portuguesa quanto línguas estrangeiras. Alguns dos aspectos do curso - dia e horário dos encontros; carga horária; isenção de taxa de matrícula - foram definidos de modo a atrair o maior número possível de professores da rede pública, já que as secretarias de educação estadual e municipais oferecem pouco ou nenhum curso de atualização para seus professores de línguas, principalmente os de língua estrangeira. Por esse motivo, as aulas foram oferecidas aos sábados pela manhã, já que, durante a semana, é muito comum os professores acumularem mais de um

\footnotetext{
* Professora Doutora na Universidade Federal de Sergipe. Endereço eletrônico: marlenesouza04@ yahoo.com.br
} 
cargo - escola estadual, municipal e/ou particular. A carga horária do curso foi de 30h (3h/a durante dez sábados), pois a política de progressão funcional da maioria das prefeituras prevê a participação em cursos de formação continuada com uma carga horária mínima de 30h/a. Além disso, não houve cobrança de taxa de matrícula. Foram matriculados quarenta professores, das quais vinte e cinco iniciaram efetivamente o curso. Nesse grupo, havia dezoito professores da rede pública e sete da rede particular.

Foram estabelecidos dois objetivos para o curso Multiletramentos Críticos e Ensino de Línguas: (1) apresentar os principais conceitos discutidos pelos teóricos de multiletramentos críticos procurando entender quais são os novos desafios a que a educação e, mais especificamente, as aulas de língua estão sendo submetidas; (2) criar condições para que os professores e futuros professores repensem suas práticas pedagógicas a partir de tais discussões e da elaboração de atividades e planos de aula.

Trato aqui este curso de extensão como um curso de formação (continuada) de professores por dois motivos. O primeiro deles está relacionado ao fato de este curso fazer parte de um programa de formação de professores da universidade. O segundo motivo está relacionado aos objetivos do curso que envolvem a apresentação teórica de questões sobre a prática pedagógica.

No caso deste artigo, o objetivo é apresentar e discutir as falas dos professores participantes quanto ao significado de multiletramentos; de crítica bem como a forma como eles entendem o papel dessas questões no ensino de línguas.

O levantamento de dados foi feito a partir da primeira atividade da primeira aula, cuja proposta era a de que os professores redigissem um parágrafo conceituando multiletramento e crítica, com base em possíveis leituras sobre o assunto, ou cursos que tenham participado, ou até mesmo com base em hipóteses que poderiam ser construídas considerando suas experiências. Depois dessa redação individual, abriu-se uma roda de conversa para os professores apresentarem oralmente o que tinham escrito sobre multiletramento e crítica. Durante as falas dos professores, a professora-formadora fazia intervenções de modo que eles esclarecessem, detalhassem mais suas opiniões ou para criar algum tipo de dúvida em relação a algumas das certezas expostas. As discussões aqui apresentadas são feitas, portanto, a partir de dois instrumentos de coleta de dados: textos dos participantes e notas de campo da pesquisadora.

\section{Revisão teórica}

Tendo em vista que os dados aqui apresentados foram levantados durante um curso de extensão com uma proposta de formação (continuada) de professores cujo objetivo era discutir multiletramentos críticos no ensino de línguas, apresento nesta seção os conceitos de língua, leitura/letramento, crítica e multiletramento crítico de acordo com os estudiosos desta linha de pesquisa.

Considerando-se as teorias dos multiletramentos críticos, língua é entendida como algo que constrói a comunicação, e não é simplesmente um instrumento utilizado pelo falante para se comunicar, para interagir. Ou seja, durante o processo de comunicação, seja através de um texto escrito, oral ou multimodal, os significados não estão com o autor ou receptor do texto, nem estão no próprio texto. Pelo contrário, os significados são construídos durante o processo de interação entre os participantes do evento.

Seguindo essa linha de raciocínio, os participantes de um evento comunicativo não podem mais ser classificados como emissor e receptor ou escritor e leitor de um texto. Ou seja, 
em um processo de comunicação, ambos os participantes têm o papel de produtores de textos, já que são responsáveis por produzir, concomitantemente, sentido em relação ao que está sendo falado/ouvido; escrito/lido. Sobre isso, Pennycook (2010) afirma que "Readers and writers are part of the fluid, urban semiotic space and produce meaning as they move, write, read and talk." (p.13).

Esses significados, atribuídos por ambos os produtores, refletem os valores, pressupostos, saberes e as representações dos grupos a que eles pertencem. Segundo Pennycook (2010):

What we do with language within different institutions - churches, schools, hospitals - for example, depends on our reading of these physical, institutional, social and cultural spaces. (p. 02).

É importante, pois, observar que atribuímos sentidos a todos os fatos que presenciamos, a todas as experiências que vivenciamos a partir de nossas próprias crenças, nossos próprios valores. Essas crenças e esses valores são construídos nas relações estabelecidas com nossos pares nos diferentes contextos, seja nas relações com os membros da nossa família; seja nas relações com pessoas da escola, do trabalho, da igreja; e mais especificamente com pessoas que compartilham as mesmas características que as nossas (idade, gênero, classe social, dentre outras). Tendemos a ler as novas informações que nos são apresentadas com base nessas leituras anteriores. Ou seja, as novas leituras sofrem 'interferências' das leituras antigas (CERVETTI; PARDALLES; DAMICO, 2001; COPE; KALANTZIS, 1999).

Isso quer dizer que os significados são construídos a partir de práticas linguísticas que não se restringem unicamente a um sistema abstrato (palavras, frases, expressões descontextualizadas), mas incluem também outros aspectos de ordem social.

Luke e Freebody (1997) estabelecem quatro elementos envolvidos na leitura como prática social: (a) práticas de codificação, que envolvem os elementos linguísticos do texto; (b) práticas de construção de sentido do texto, em que o leitor precisa identificar as ideias representadas no texto, os recursos culturais que podem suportar tais ideias e os possíveis significados culturais que podem ser atribuídos ao texto; (c) práticas de pragmática, momento em que o leitor procura definir se o texto será útil para ele e para outras pessoas, e quais são as opções e alternativas que o texto lhe oferece; (d) e práticas críticas.

No que diz respeito ao último elemento, que trata das práticas críticas, Luke e Freebody (1997); Cervetti; Pardales e Damico (2001), dentre outros, afirmam que ser crítico não significa identificar a intenção do autor ou quais as estratégias que estão sendo usadas para convencer e/ou manipular o outro. Tendo em vista que para eles, os textos representam posições, ideologias e discursos culturais, pois,tanto quem escreve quanto quem lê um texto recorrem a recursos culturais para a produção de sentido, esse processo não é neutro. E, dentro desse processo, identificar o contexto social, histórico e de relações de poder em que o texto está inserido e foi produzido, bem como questionar as próprias visões de mundo, valores, crenças refletidos nas nossas leituras, na forma como construímos sentidos sobre tudo o que os rodeia, torna-se relevante para a compreensão do significado, caso contrário o que prevalece é o modelo reprodutivo de significado, no qual pode predominar a assimilação e colonização cultural.

Não se questiona aqui o fato de as pessoas recorrerem aos valores do grupo a que pertencem para construírem sentidos sobre tudo o que as cerca. O que se propões é que as pessoas estejam constantemente analisando e discutindo as limitações e implicações de cada perspectiva adotada, possibilitando a identificação do modo pelo qual um assunto é entendido, 
porque é entendido daquela forma, quais são as outras formas de se analisar aquele assunto e quais as consequências de se adotar uma ou outra perspectiva (MENEZES DE SOUZA; MONTE MÓR, 2006; MENEZES DE SOUZA; ANDREOTTI, 2008).

Entendendo-se leitura como uma prática social, o papel da escola não fica restrito única e exclusivamente à alfabetização, ou seja, desenvolver no aluno o domínio das técnicas de codificação e decodificação. Para diferenciar, autores como Rojo (1998), Soares (2004) usam o termo letramento, que significa ensinar e aprender as práticas sociais de leitura e escrita que estão relacionadas a saber fazer uso das várias e diversas práticas sociais da leitura e da escrita - leitura de livros, jornais, revistas; escrita de oficio, requerimento, declaração.

No que diz respeito à palavra crítica, em letramento crítico, Luke e Freebody (1997) afirmam que os principais aspectos que distinguem o letramento do letramento crítico são: (a) leitura e escrita são vistas como atividades sociais, já que lemos textos escritos por alguém e escrevemos para alguém; (b) todos os textos são motivados - não é possível ler ou escrever um texto de uma posição neutra, porque os textos representam os interesses de um determinado grupo; (c) a língua, o dialeto ou o estilo de comunicação varia de acordo com o interlocutor; (d) os textos deixam transparecer as várias identidades de quem os produziu e tais identidades estão relacionadas a interesses culturais e políticos.

Além disso, no letramento crítico os objetivos de leitura não se restringem apenas a identificação das informações gerais, principais e detalhadas, mas também: (a) quebra do senso comum: os alunos precisam aprender que os significados são socialmente construídos; (b) considerar as idéias de diferentes pontos de vista: os alunos precisam ter a oportunidade de refletir sobre alguns assuntos considerando um ponto de vista que seja diferente daqueles a que eles estão acostumados; (c) considerar os aspectos sociais e políticos que estão refletidos em um texto; (d) ajudar os alunos a agir e promover justiça social: o letramento critico envolve perguntas sobre os estereótipos presentes em um determinado tipo de texto, ou perguntas que fazem os alunos identificarem as perspectivas que não estão presentes (normalmente a perspectiva da minoria) (WARD; BEACH; MIRSEITOVA, 2004).

Portanto, o professor de línguas precisa apresentar atividades aos alunos que permitam a eles identificarem de que forma os textos, principalmente os que temos acesso diariamente (notícias, propagandas, por exemplo), são organizados. Toda a organização do texto, incluindo a parte lexical, sintática e semântica, retrata um determinado mundo e encaminha a forma como será feita a leitura deste mundo. Ao desenvolverem a crítica, os alunos podem ver através dos textos, identificar os conceitos de culturas e de mundo apresentados, e como tais textos estão tentando posicionar o leitor em relação às culturas e aos mundos dos quais eles fazem parte. Um aspecto bastante importante nas práticas pedagógicas que envolvem o letramento crítico diz respeito a criar condições para que os alunos tomem consciência do como, do porquê, e aos interesses de quem um determinado texto está a serviço, conforme indicam Luke e Freebody (1997):

To teach critical literacy thus encourages the development of alternative reading positions and practices for questioning and critiquing texts and their affiliated social formations and cultural assumptions. It also entails developing strategies for talking about, rewriting, and contesting the texts of everyday life. (p.218).

No que diz respeito ao prefixo multi diante da palavra letramento, é importante lembrar que o termo letramento foi criado na era tipográfica, quando os textos eram lineares, escritos da 
esquerda para a direita, de cima para baixo, e com a possibilidade apenas de palavras e/ou imagens impressas. Atualmente, segundo Lemke (2007), as novas tecnologias estão nos levando da era da 'escrita' para a era da 'autoria de multimídia', já que permite integrar aos textos, imagens em movimento e sons que mudam o caráter da comunicação. Para a leitura ou a elaboração de um hipertexto são necessárias não apenas as ferramentas tecnológicas (hardware/software), mas também novas habilidades relacionadas à autoria e à interpretação. Segundo Lemke, as habilidades a serem desenvolvidas por conta da Era da Informação são as seguintes: de autoria de multimídia; de análise crítica de multimídia, de estratégias de exploração do ciberespaço, e de navegação no ciberespaço. Considerando-se as novas necessidades dos alunos para a participação na sociedade, as escolas precisam repensar seu papel no sentido de oferecer aos alunos não apenas informações relacionadas ao letramento do texto impresso, mas também desenvolver os novos letramentos que incluem letramento visual, da informação e da mídia (SCHWARZ, 2004), ou seja, multiletramentos.

Entendo, portanto, que o encaminhamento de discussões sobre os multiletramentos críticos pode, de alguma forma, contribuir para a formação continuada dos professores. $\mathrm{O}$ curso pode ser uma oportunidade para os professores refletirem sobre suas escolhas quanto ao conteúdo, às estratégias, bem como à avaliação. Dessa forma, eles podem reconhecer que suas escolhas pedagógicas são resultantes de suas perspectivas quanto ao que seja ensinar, aprender, papel do aluno, do professor e que tais escolhas determinam o tipo de aluno que está sendo formado. Isso quer dizer que os cursos de formação continuada podem ser o único espaço onde os professores tenham condições de fazer uma análise de forma sistemática de suas escolhas pedagógicas. Por esse motivo, acho importante que tais cursos criem condições para que os professores analisem as abordagens de ensino a partir de pontos de vista diferentes daqueles a que estão acostumados. Dessa forma, é possível que eles se posicionem em relação aos seus valores assumindo-os, rejeitando-os ou reconstruindo-os, e, segundo Schwarz (2004), adotar uma prática pedagógica baseada nos (multi)letramentos críticos pode orientar a decisão dos professores em manter ou transformar a sociedade.

\section{Professores (em formação) (re)conceituando (multi)letramentos e crítica no ensino de línguas}

Apresento e discuto nesta seção os conceitos que os professores do curso Multiletramentos Críticos e Ensino de Línguas apresentaram para (multi)letramentos e crítica quando se trata do ensino de línguas. As falas dos professores aqui apresentadas foram levantadas nos textos que eles escreveram conceituando esses termos, ou nas notas de campo da professora formadora feitas durante as discussões com todo o grupo.

\section{1 (Re)conceituando multiletramentos}

No primeiro encontro do curso Multiletramentos Críticos e Ensino de Línguas, as discussões foram orientadas de modo a permitir que os professores participantes tivessem a oportunidade de refletir e (re)conceituar os termos (multi)letramentos e crítica. Não foi apresentado nenhum embasamento teórico sobre o assunto a priori, porque se pretendia chamar a atenção dos professores para os seguintes aspectos que envolvem os multiletramentos críticos: (a) sempre conseguimos construir sentido sobre qualquer assunto, porque recorremos aos nossos 
conhecimentos resultantes das relações estabelecidas nas mais diferentes situações (em casa, na escola, no trabalho, nas horas livres, dentre outras); (b) os sentidos são construídos diferentemente de acordo com os contextos sócio-histórico-ideológicos a que pertencemos; (c) como os contextos são múltiplos e diversos, não é possível falar em uma única verdade, por esse motivo, o importante é identificar as limitações e consequências de se adotar uma ou outra verdade (CERVETTI; PARDALLES; DAMICO, 2001; COPE; KALANTZIS, 1999; LUKE; FREEBODY, 1997; SNYDER, 2002).

Inicialmente, os professores tiveram que conceituar letramento. A maioria deles afirma entender que essa palavra seja sinônima de alfabetização:

Prof1: Letramento significa alfabetização.

Prof2: Letramento tem alguma relação com alfabetização.

Prof3: Os professores da educação básica usam o termo letramento quando se referem à alfabetização. (grifos meus)

Portanto, para eles, essas duas palavras podem ser utilizadas indistintamente. No entanto, para Soares (2004), essas palavras não são sinônimas, já que alfabetização está relacionada basicamente ao processo de ensinar as crianças a (de)codificarem as palavras, ou seja, ensina-se inicialmente as letras do alfabeto e depois as sílabas para a formação das palavras. Já o termo letramento está relacionado à prática social da língua, em que os sentidos das palavras são construídos no processo interativo e não são fixos, transparentes ou neutros.

No que diz respeito a uma abordagem de ensino que considere o letramento crítico, os participantes do curso argumentam que não seja possível abordar o letramento crítico antes que as crianças sejam alfabetizadas, ou seja, eles entendem que alfabetização e letramento crítico são dois momentos distintos e interdependentes no processo de ensino de línguas.

Prof7: O processo de letramento crítico deve acontecer depois que a criança já está alfabetizada.

Prof10: Não é possível alfabetizar e discutir criticamente ao mesmo tempo.

Prof13: As crianças não têm senso crítico, só depois que estão maiores é que entendem algumas coisas.

Para esses professores, portanto, as crianças de 6/7 anos (idade em que os alunos começam a ser alfabetizados em escolas brasileiras) não têm condições de fazer uma leitura crítica, pois não têm maturidade ("As crianças não têm senso crítico....") e tampouco dominam as 'ferramentas' básicas da língua ("Não é possivel alfabetizar e discutir criticamente ao mesmo tempo”), que estão relacionadas principalmente aos aspectos sintáticos, semânticos e fonéticos.

No entanto, alguns pesquisadores, como Soares (2004) têm discutido letramento não apenas com essa ideia de decodificação. Para a autora, há uma diferença entre alfabetização e letramento. Aquela está focada basicamente no ensinar a ler e escrever, de um ponto de vista mais técnico e mecânico que envolve o processo de codificação e decodificação, sem uma ênfase em questões relacionadas ao contexto.

Diferentemente das ideias relacionadas ao conceito tradicional de alfabetização, o letramento apresenta-se em duas dimensões - individual e social. Segundo Soares (2004), é preciso criar condições para que as pessoas não desenvolvam apenas o nível da codificação e decodificação - dimensão individual do letramento, mas também que aprendam a ler e a escrever no contexto de acordo com as necessidades, valores e práticas sociais da leitura e da escrita - 
dimensão social do letramento, ou seja, que leiam livros, jornais, revistas, saibam redigir um oficio, um requerimento, uma declaração. Para Soares (2004):

[...] o indivíduo letrado, é aquele que vive em estado de letramento, é não só aquele que sabe ler e escrever, mas aquele que usa socialmente a leitura e a escrita, pratica a leitura e a escrita, responde adequadamente às demandas sociais de leitura e de escrita (p.40).

Outros autores como Lankshear e Knobel (2003), Lankshear; Snyder e Green (2000), apesar de não fazerem referência à alfabetização, discutem a questão do letramento a partir de uma perspectiva bastante parecida. Esses autores afirmam que o letramento envolve tanto as regras gramaticais como também as práticas sociais, o que torna a leitura um processo de construção de sentido e não apenas de decodificação. Sendo assim, não é possível falar que o aprendizado de uma língua aconteça em dois momentos distintos: primeiro, aprende-se sua estrutura - alfabetização; depois, aprende-se seu uso social - letramento.

Entender o ensino de línguas não a partir do conceito de alfabetização e sim a partir do letramento crítico implica considerar que a construção de significado representa o conhecimento do leitor em relação a si mesmo e em relação ao mundo, independente de sua idade, classe social, ou grau de instrução. Ou seja, os sentidos são atribuídos a partir de lentes (MENEZES DE SOUZA; ANDREOTTI, 2008) construídas nas complexas redes estabelecidas em contextos específicos (cultura, mídias, religiões, educação, etc.) e nas interações com os outros. Consequentemente, as pessoas envolvidas na construção de sentido são influenciadas pelos pressupostos e pelas perspectivas de seus interlocutores, bem como também os influenciam.

Se todo texto é, portanto, uma prática social e os sentidos são construídos socialmente, o conceito de alfabetização/letramento apresentado pelos professores do curso é incoerente. Mesmo que as atividades propostas com base em um texto (verbal e/ou não verbal) foquem, aparentemente, apenas os aspectos técnicos, mecânicos da língua, em que o aluno precise ativar suas habilidades de codificação ou decodificação, as crenças construídas socialmente, estão presentes, refletidas nas escolhas que fazemos das palavras, expressões, imagens que serão ou não utilizadas para produzir ou interpretar um texto. Ao codificar e/ou decodificar a palavra casa, por exemplo, ao mesmo tempo em que há uma preocupação em saber se é escrita com $S$ ou $Z$, os alunos acionam todos os seus valores, as suas crenças formando imagens mentais. Ou seja, independentemente de o professor solicitar ou não, eles imaginarão a casa que o grupo a que eles pertencem os ensinaram a entender como casa-de alvenaria ou uma oca como a de muitos índios ou um barco como de uma comunidade que vive em alto mar.

\section{$3.2(\operatorname{Re})$ conceituando crítica}

Como o objetivo do curso era discutir multiletramentos críticos e o ensino de línguas, além de os professores apresentarem os conceitos que tinham sobre letramento, eles também tiveram que falar o que entendiam por crítica. Apresento, aqui, trechos de seus textos ou de suas falas durante as discussões.

No que diz respeito à reflexão crítica, os professores a entendem como estando relacionada ao conhecimento sobre o tema, ou seja, segundo eles só é possível fazer uma análise crítica sobre uma questão quando a dominamos. 
Prof1: Para criticar alguma coisa precisamos dominar o assunto.

Prof4: As crianças não conseguem ver as questões de forma crítica, porque são muito novas e não têm muitas informações sobre os assuntos.

Prof17: Só podemos ter uma opinião crítica sobre um assunto se pesquisarmos bastante sobre ele.

A partir de colocações como essas, de que é preciso ter muito conhecimento sobre um assunto para ser crítico, perguntei aos professores participantes qual ou quais conhecimento(s) uma pessoa precisaria ter para ter condições de se posicionar criticamente.

Em um primeiro momento, todos concordaram que o conhecimento científico é o principal, mas que o conhecimento da cultura popular, adquirido nas relações com o grupo, deve ser respeitado.

Prof9: É, acho que não precisa ser conhecimento só de livro.

Prof16: É, e Paulo Freire fala de partirmos dos conhecimentos que os alunos já trazem pra escola.

Ou seja, as falas dos professores 1,4 e 7 relacionavam crítica a um conhecimento formal, aprofundado. A partir do meu questionamento sobre a que tipo de conhecimento eles estavam se referindo, os professores 9 e 16 apresentaram um conceito de conhecimento diferente, que não estava restrito ao científico. Nas falas deles é possível perceber que eles consideram o fato de que todas as pessoas dominam algum tipo de conhecimento independentemente de terem frequentado as escolas ou de terem acesso aos conhecimentos disseminados nos livros, nas enciclopédias, nas escolas, universidades ( “...conhecimento (não) só de livro.”; "conhecimentos que os alunos já trazem da escola”). Tal opinião poderia indicar que os professores não têm uma visão tradicional de crítica, cujo sentido está relacionado à ideia de que apenas as pessoas com autoridade legitimada, aquelas que possuem algum tipo de diploma (médicos, professores, advogados) ou algum título (presidente, bispo), teriam todo o embasamento teórico e as condições intelectuais de apresentar os fatos verdadeiros, como eles realmente são (CERVETTI; PARDALLES; DAMICO, 2001; MENEZES DE SOUZA; ANDREOTTI, 2008).

Para confirmar se os professores realmente reconheciam tanto o conhecimento acadêmico quanto o popular, perguntei a eles se qualquer pessoa poderia ser professor, mesmo que não tivesse algum curso específico, mas que tivesse conhecimento do conteúdo a ser ensinado.

Prof2: Nesse caso eu acho que não. Para ser professor não basta ter conhecimento do conteúdo, dos assuntos da disciplina.

Prof7: Com certeza, é preciso conhecimento pedagógico. O professor precisa saber as técnicas pra ensinar.

Prof13: É na faculdade que a gente aprende de que forma um conteúdo pode ser transmitido, quando o aluno está preparado para aprender.

Prof17: Não basta ser nativo pra ensinar uma língua, tem que conhecer as estratégias de ensinar.

A partir desses depoimentos, é possível perceber que os professores defendem a ideia de que, para ser professor, é preciso tanto o conhecimento do conteúdo que não necessariamente tenha sido adquirido na faculdade ("ser nativo") quantos os conhecimentos "pedagógicos", das "técnicas", das "estratégias", adquiridos "na faculdade". 
No conceito tradicional, o conhecimento é adquirido através do pensamento racional, de uma análise racional da realidade. Consequentemente, só se considera verdade e informação válida o que for transmitido pela ciência, já que sua linguagem é objetiva. Nessa linha de raciocínio, outras fontes de informação são passíveis de serem questionadas por serem entendidas como fatos, inferências e julgamentos do leitor. O conhecimento reconhecido, aceito é aquele validado pela linguagem da ciência e pertence a, e é disseminado por um determinado grupo que controla as ideologias, instituições e práticas da sociedade (CERVETTI; PARDALLES; DAMICO, 2001).

No entanto, o que precisa ser discutido é que o conhecimento não é natural ou neutro, pois está sempre baseado nas regras discursivas de uma determinada comunidade o que o torna ideológico. Por conseguinte, esse conhecimento transmitido por escolas, universidades está 'contaminado' pelas crenças e valores que um determinado grupo tem sobre o mundo, a sociedade e o papel da educação.

Defender a ideia de que apenas podem ser professores as pessoas que foram preparadas por uma instituição reconhecida, com autorização para transmitir um conhecimento científico as técnicas pra ensinar; as estratégias de ensinar - é ignorar o fato de que o conhecimento é construído nas relações sociais e, portanto, é sempre parcial, complexo e dinâmico (CERVETTI; PARDALLES; DAMICO, 2001; MENEZES DE SOUZA; ANDREOTTI, 2008).

Depois de serem discutidas essas questões, os professores chegaram a duas conclusões que, em minha opinião, são contraditórias. Por um lado, eles concordaram que seria possível considerar uma pessoa como sendo professora mesmo que ela não tenha nenhum conhecimento pedagógico adquirido nas instituições reconhecidas por transmitirem conhecimento científico.

Prof3: Os caciques das tribos são os responsáveis por transmitir a cultura de seus povos para os mais novos.

No entanto, apesar de esses professores afirmarem que um cacique pode ter um conhecimento reconhecido para ser transmitido ao seu grupo, a reflexão crítica só pode ser associada a pessoas com conhecimento científico, ou seja, para ser crítico não basta apenas ter conhecimento sobre o assunto, o professor só adquire senso crítico se frequentar um curso superior e adquirir uma formação pedagógica.

Prof14: É preciso discutir com os alunos a importância de fazer faculdade, só assim eles poderão ter uma opinião crítica sobre as coisas.

Prof23: Com certeza, os alunos precisam perceber que se eles não estudarem eles ficam no senso comum.

A partir de ideias como essas, entendo que, para os professores, o conceito de crítica é o tradicional, em que a reflexão crítica está relacionada à capacidade de identificar o que é certo e, consequentemente, identificar o valor de verdade que foi estabelecido por uma pessoa, instituição autorizadas (faculdade) (CERVETTI; PARDALLES; DAMICO, 2001; LANKSHEAR; KNOBEL, 2003). Na situação descrita, os professores participantes do curso parecem estar convencidos de que é um fato que uma pessoa só pode ser crítica se frequentar uma faculdade para adquirir o conhecimento científico, do contrário, ela fica no senso comum, não tem opinião crítica. Esses professores parecem não perceber que suas falas expressam uma opinião, baseada em uma crença compartilhada e sustentada por argumentos construídos por um grupo. 
Essa perspectiva de crítica não considera que o conhecimento e a verdade são sempre parciais e dependentes do contexto e, portanto, são complexos e dinâmicos, como defendem os autores que discutem os multiletramentos críticos (CERVETTI; PARDALES; DAMICO, 2001; GEE, 2004). A reflexão crítica consiste, portanto, na capacidade de perceber como as crenças são construídas nos mais diferentes contextos, questionando-se, por exemplo, o porquê de eu acreditar ser necessário conhecimento pedagógico para ser professor. Além disso, ser crítico exige um constante questionar sobre o como construímos os sentidos dos textos que nos rodeiam. A partir da identificação das origens das nossas crenças - penso assim porque todas as pessoas dos grupos a que pertenço acreditam que para ser professor é necessário conhecimento pedagógico - é possível questionar as implicações positivas e/ou negativas de se concordar ou, adotar tal perspectiva - pessoas que não frequentaram escolas, caciques, por exemplo, têm seus conhecimentos não-acadêmicos questionados e, em alguns casos, desrespeitados, por pessoas que adquiriram seus conhecimentos nas universidades. Nesse caso, desconsidera-se que, dependendo da comunidade, os conhecimentos necessários para o grupo são adquiridos diferentemente caciques aprendem os segredos das ervas, das orações dos mais velhos durante determinados rituais. Ou seja, não é possível estabelecer valores para os conhecimentos adquiridos em um e outro contexto, exatamente por apresentarem características diferentes.

\section{Considerações finais}

A partir da análise das falas dos professores participantes de um curso de extensão, foi possível identificar quais os significados atribuídos por eles a multiletramentos; à crítica e ao papel dessas questões no ensino de línguas.

Os professores conceituam (multi)letramentos e crítica em uma perspectiva mais tradicional. Para eles, letramento é sinônimo de alfabetização e consiste na aprendizagem do sistema abstrato da língua. Crítica é associada à habilidade para identificar o certo/errado; verdadeiro/falso das ideias presentes em um texto seja ele verbal, não verbal, multimodal. E, para esses professores, ensinar (multi)letramentos críticos nas aulas de línguas (portuguesa ou estrangeira) só é possível se o aluno já domina as regras básicas da língua depois das séries iniciais de escolarização, porque é quando ele já adquiriu um conhecimento além daquele do senso comum.

Como discutido ao longo deste artigo, os conceitos apresentados pelos professores são resultantes de suas experiências, das crenças e dos valores compartilhados pelos integrantes dos grupos de que eles fazem parte. Partindo desse pressuposto, o curso foi planejado para ser um espaço de desenvolvimento de reflexividade dos professores participantes. Muito mais do que simplesmente apresentar os conceitos de multiletramentos críticos de teóricos da área, o objetivo inicial era de criar condições para que os professores participassem de um processo de elaboração dos conceitos desses termos. Como tal processo consistiu de discussões com o grupo caracterizado principalmente por perguntas feitas pela professora formadora, os professores puderam (res)significar enquanto (re)pensavam sobre as ideias que eram a base sobre a qual eles estavam conceituando multiletramentos, crítica e ensino de línguas.

\section{Referências}


CERVETTI, G. PARDALES, M. J.; DAMICO, J. S. A tale of differences: comparing the traditions, perspectives, and educational goals of critical reading and critical literacy. 2001. Reading Online, 4(9). Disponível em <http://www.readingonline.org/articles/art_index.asp?HREF=cervetti/index.html $>$. Acesso em: 14 julho 2005.

COPE, B. ; KALANTZIS, M. Multiliteracies: Literacies Learning and the Future of Social Futures. Londres: Routledge Taylor \& Francis Group, 1999.

FESTINO, C. G. Rewriting the Foreign Literature Syllabus from the Perspective of Critical Literacy. Critical Literacy: Theories and Practices, v. 2, n.1, 2008. p. 06-15. Disponível em: <http://www.criticalliteracyjournal.org/>. Acesso em: 20 agosto 2010.

GEE, J. P. Situated Language and Learning:a critique of traditional schooling. New York: Routledge, 2004.

JORDÃO, C. M. South-North Dialogue on Globalization Research: a non-typical Brazilian perspective. Globalization and Autonomy, 2008. v. 1.

LANKSHEAR, C.; KNOBEL, M. New Literacies: Changing knowledge and classroom learning. Buckingham/Philadelphia: Open University Press, 2003.

LANKSHEAR, C.; SNYDER, I.; GREEN, B. Teachers and technoliteracy: managing literacy, technology and learning in schools. Sydney: Allen and Unwin, 2000.

LEMKE, 2007. Metamedia Literacy: Transforming meanings and media. 2007. Disponível em http://academic.brooklyn.cuny.edu/education/jlemke/reiking.htm. Acesso em out.2007.

LUKE, A.; FREEBODY, P. Shaping the Social Practices of Reading. In MUSPRATT, S.; LUKE, A.; FREEBODY, P (Ed.). Constructing Critical Literacies:Teaching and Learning Textual Practice. Nova Jersey: Hampton Press, Inc., 1997.

MENEZES DE SOUZA, L. M. T.; ANDREOTTI, V. Learning to Read the world through other eyes. Derby, Inglaterra: Global Education, 2008.

MENEZES DE SOUZA, L. M. T.; MONTE MÓR, W. Conhecimentos de Línguas Estrangeiras. Brasília: Ministério de Educação, 2006. p. 85-124. v. 1. Em: Secretaria de Educação Básica, Ministério de Educação. (Org.). Orientações Curriculares para O Ensino Médio: Linguagens, Códigos e suas Tecnologias.

PENNYCOOK, A. Language as a local practice. Nova York: Taylor \& Francis, 2010.

ROJO, R. H. R. O. Letramento na ontogênese: uma perspectiva socioconstrutivista. In: (Org.). Alfabetização e Letramento. São Paulo: Mercado de Letras, 1998.

SCHWARZ, G. Graphic Novels: Multiple Cultures and Multiple Literacies. International Reading Association, Thinking Classroom. v, 5, p.17-24. n. 4. 2004. 
SNYDER, I. (Ed.). Silicon Literacies: Communication, Innovation and Education in the Electronic Age. London: Routledge, 2002.

SOARES, M. Letramento: um tema em três gêneros. Belo Horizonte: Autêntica, 2004.

TAKAKI, N. H. Letramentos na sociedade digital: navegar é e não é preciso. São Paulo: 2008. 199f. Tese (Doutorado em Estudos Linguísticos e Literários em Inglês) Faculdade de Letras e Ciências Humanas, Universidade de São Paulo, São Paulo, 2008.

WARD, A.; ANN BEACH, S.; MIRSEITOVA, S. Teacher's Understandings of Critical Literacy: An exploratory International Study. International Reading Association, Thinking Classroom. v. 5, n. 3, p.15-22, 2004.

Recebido em: maio de 2013.

Aprovado em: agosto de 2013. 